\title{
Симметрика синтаксических фигур в художественной прозе: на материале русского рассказа XX века
}

\author{
Г.Я. Мартыненко ${ }^{1}$ Т.Ю. Шерстинова ${ }^{1,2}$ \\ ${ }^{1}$ Санкт-Петербургский государственный университет, ${ }^{2}$ Национальный исследовательский \\ университет Высшая школа экономики \\ g.martynenko@gmail.com, sherstinova@gmail.com
}

\section{Аннотация}

Статья посвящена исследованию линиаризованных соподчинительных структур, которые в теории зависимостей называются шириной куста. Исследование имеет квантитативный характер. В нем используются ранговые распределения фигур, в которых фиксируется не только число зависимых членов, но и варианты их расположения справа (в постпозиции) или слева (в препозиции) относительно вершины дерева предложения. Установлен факт сходства ранговых структур у разных авторов при существенном различии частотных характеристик. В работе рассматриваются симметрийные свойства кустовых фигур, их тяготения к зеркальной и золотой симметрии. Установлено примерное равновесие левой и правой ширины в русском рассказе первой трети XX века. Протестирован на предмет адекватности русскому языку и скорректирован закон нарастающих членов предложения немецкого филолога Отто Бехагеля.

Ключевые слова: русский рассказ, ранговые распределения, ранговое среднее, индекс концентрации, синтаксические фигуры, правая и левая ширина, симметрия куста, зеркальная симметрия, золотая симметрия, закон Бехагеля

Библиографическая ссылка: Г.Я. Мартыненко, Т.Ю. Шерстинова Симметрика синтаксических фигур в художественной прозе: на материале русского рассказа XX века // Компьютерная лингвистика и вычислительные онтологии. Выпуск 3 (Труды XXII Международной объединенной научной конференции «Интернет и современное общество», IMS-2019, Санкт-Петербург, 19 - 22 июня 2019 г. Сборник научных трудов). - СПб: Университет ИТМО, 2019. С. 116 -123. DOI: 10.17586/2541-97812019-3-116-123

\section{1. Введение}

В работе (Мартыненко, 1988) приводится развернутая классификация мер синтаксической сложности. В частности, выделяются меры иерархической сложности, построенные на механизмах параллельного и последовательного подчинения в рамках грамматики зависимостей. В статье ставится задача изучения линеаризованных вариантов таких структур, закономерностей их группирования около конструктивного центра предложения и тенденций, возникающих в цепочке членов предложения, следующих друг за другом, разноудаленных от вершины и обладающих при этом различной словесной массой.

\section{2. Ранговое распределение синтаксических фигур}

Объект исследования - линеаризованные структуры зависимостей (Фитиалов, 1968; Буторов, 1996). Рассматриваются структуры с соподчинением. В дереве зависимостей их называют кустами. Такие структуры содержат вершину и группу зависимых членов, 
расположенных слева (в препозиции) и справа (в постпозиции) от вершины. Зависимые члены группируются слева и справа в разном соотношении.

В нашей работе исследовались пять рассказов: «В толпе» Федора Сологуба, «Тридцать три урода» Лидии Зиновьевой-Аннибал, «Эмалиоль» Алексея Ремизова, «Год их жизни» Бориса Пильняка и «Реки огненные» Артема Веселого. В этих рассказах исследовались кусты, в которых вершина является конструктивным центром предложения. Результаты сплошного наблюдения представлены в табл. 1.

Сравним эти ранговые распределения. Сделаем это сначала «на глазок». Обратим внимание на самые существенные моменты. Несмотря на заметные различия в объеме рассказа, число разноименных фигур по авторам варьирует значительно слабее, составляя от 16 до 21 единицы. При этом во всех списках первое место занимает структура 1:1, а топовые десятки по составу практически совпадают. Важен также и тот факт, что количество левых и правых зависимых сдерживается максимальным значением ширины, характерным для естественных языков. Такие соотношения как 5:3 (в сумме 8), просто невозможны даже в гигантских выборках. Здесь присутствует откровенный верхний предел. Это имеет последствием тот факт, что даже в нашем материале несмотря на то, что все рассказы сильно отличаются по объему, число разноименных элементов, равное максимальному в данном рассказе рангу синтаксической фигуры, варьирует в весьма узких границах (см. табл. 1). Следует ожидать, что в более крупных произведениях значения максимального ранга будут одинаковы.

Последнее наблюдение говорит также о том, что все наши ранговые распределения по оси рангов по мере увеличения объема выборки будут стремиться к выравниванию величины максимального ранга. В низкочастотной зоне число разноименных элементов прекратит свой рост. Такая «размазанность», «длиннохвостость» рангового распределения исчезает, хотя неравномерность распределения частот сохраняется.

Обнаруженная нами качественная сторона таких распределений, по-видимому, может оказаться особым разделом теории ранговых распределений.

Попытаемся теперь сравнить наши списки с помощью обобщающих характеристик. Для этого используем две нестандартные статистики: ранговое среднее, которое вычисляется так же как обычное среднее, но только в качестве варьирующего признака выступает ранг, а в качестве статистических весов - соответствующие ему частоты (Мартыненко, 1988, с. 80-82); индекс концентрации К, вычисляемый по формуле (Мартыненко, 1989):

$$
K=1-\frac{r_{\mathrm{y}}}{r_{\mathrm{B}}} \text {. }
$$

где $r_{\mathrm{y}}$ - ранговое среднее убывающего рангового распределения, а $r_{\text {в }}$ возрастающего.

Из табл. 1 видно, что ранговые средние пяти рассказов и индексы концентрации соответствующих распределений варьируют весьма умеренно, при этом индекс концентрации во всех случаях довольно велик (больше 0,7), что говорит о довольно большом скоплении частот в верхней зоне пяти ранжировок.

Недостатком двух упомянутых нами статистик является их довольно-таки сильная зависимость от объема выборки (Мартыненко, 1988; Гребенников, 1999). Эти недостаток преодолевается с помощью порядковых статистик, например, медианы. Последняя практически состоятельна, не реагируя на расширение объема наблюдения (Мартыненко, 2017). Ее значения для пяти рассказов приведены в последней строке табл. 1.

Именно величина медианы устойчиво характеризует сходство и различия между ранговыми распределениями синтаксических фигур.

\section{3. Симметрийные свойства синтаксических фигур}

Данные табл. 1 позволяют оценить тяготение конкретного прозаика к симметричным и асимметричным структурам (Мартыненко, 2016). 
Разделим все соподчиненные структуры на три класса: симметричные, асимметричные влево и асимметричные вправо.

К первой группе относятся такие структуры: 0:0, 1:1, 2:2 и т. д.

Ко второй группе относятся структуры вида: 1:0, 2:0, .; 2:1, 3:1, .,; 3:2, 4:2 и др.

Третью группу образуют фигуры типа: $0: 1,0: 2, \ldots ; 1: 2,1: 3, \ldots ; 2: 3,2: 4$ и др.

Таблица 1. Ранговые распределения линеаризованных соподчинительных (кустовых) фигур в рассказах пяти авторов

\begin{tabular}{|c|c|c|c|c|c|c|c|c|c|c|c|c|}
\hline \multirow[t]{2}{*}{ Ранги } & \multicolumn{2}{|c|}{ Сологуб } & \multicolumn{2}{|c|}{$\begin{array}{c}\text { Зиновьева- } \\
\text { Аннибал }\end{array}$} & \multicolumn{2}{|c|}{ Пильняк } & \multicolumn{2}{|c|}{ Ремизов } & \multicolumn{2}{|c|}{$\begin{array}{c}\text { Артем } \\
\text { Веселый }\end{array}$} & \multicolumn{2}{|c|}{ Сумма } \\
\hline & $\begin{array}{c}\text { Фигу- } \\
\text { pa }\end{array}$ & Кол-во & $\begin{array}{c}\text { Фигу- } \\
\text { ра }\end{array}$ & Кол-во & $\begin{array}{c}\text { Фигу- } \\
\text { ра }\end{array}$ & Кол-во & $\begin{array}{c}\text { Фигу- } \\
\text { pa }\end{array}$ & Кол-во & $\begin{array}{c}\text { Фигу- } \\
\text { ра }\end{array}$ & Кол-во & $\begin{array}{c}\text { Фигу- } \\
\text { ра }\end{array}$ & Кол-во \\
\hline 1 & $1: 1$ & 295 & $1: 1$ & 187 & $1: 1$ & 126 & $1: 1$ & 110 & $1: 1$ & 165 & $1: 1$ & 883 \\
\hline 2 & $0: 1$ & 164 & $1: 0$ & 98 & $0: 1$ & 72 & $1: 0$ & 72 & $0: 1$ & 153 & $0: 1$ & 520 \\
\hline 3 & $2: 1$ & 75 & $2: 1$ & 79 & $0: 2$ & 37 & $0: 1$ & 60 & 1:0 & 132 & 1:0 & 380 \\
\hline 4 & $1: 2$ & 73 & $0: 1$ & 71 & $2: 1$ & 34 & $2: 1$ & 59 & $0: 0$ & 89 & $2: 1$ & 285 \\
\hline 5 & $1: 0$ & 71 & $2: 0$ & 56 & $1: 2$ & 30 & $2: 0$ & 45 & $2: 0$ & 45 & $1: 2$ & 217 \\
\hline 6 & $0: 0$ & 51 & $1: 2$ & 54 & $0: 0$ & 12 & $1: 2$ & 37 & $2: 1$ & 38 & $0: 0$ & 214 \\
\hline 7 & $0: 2$ & 44 & $0: 0$ & 36 & $2: 2$ & 9 & 0:0 & 26 & $0: 2$ & 36 & 2:0 & 179 \\
\hline 8 & $2: 0$ & 26 & $2: 2$ & 30 & $0: 3$ & 9 & $0: 2$ & 23 & $1: 2$ & 23 & $0: 2$ & 169 \\
\hline 9 & $2: 2$ & 16 & $0: 2$ & 29 & 2:0 & 7 & $3: 0$ & 18 & $3: 1$ & 12 & $2: 2$ & 72 \\
\hline 10 & $0: 3$ & 9 & $3: 1$ & 27 & 1:0 & 7 & $3: 1$ & 15 & $3: 0$ & 11 & $3: 1$ & 68 \\
\hline 11 & $3: 1$ & 8 & $3: 0$ & 21 & $3: 1$ & 6 & $2: 2$ & 13 & $0: 3$ & 6 & $3: 0$ & 59 \\
\hline 12 & $1: 3$ & 7 & $1: 3$ & 10 & $1: 3$ & 5 & $1: 3$ & 10 & $2: 2$ & 4 & $1: 3$ & 35 \\
\hline 13 & $3: 0$ & 6 & $3: 2$ & 4 & $3: 0$ & 3 & $4: 0$ & 5 & $4: 1$ & 3 & $0: 3$ & 32 \\
\hline 14 & $2: 3$ & 4 & $0: 3$ & 4 & $1: 4$ & 2 & $0: 3$ & 4 & $1: 3$ & 3 & $4: 0$ & 13 \\
\hline 15 & $3: 2$ & 3 & $4: 0$ & 4 & $4: 1$ & 2 & $4: 1$ & 3 & $4: 0$ & 1 & $4: 1$ & 12 \\
\hline 16 & $4: 0$ & 2 & $4: 1$ & 3 & $2: 3$ & 2 & $3: 2$ & 2 & $5: 0$ & 1 & $3: 2$ & 10 \\
\hline 17 & $4: 2$ & 1 & $2: 3$ & 1 & $4: 0$ & 1 & $3: 3$ & 2 & & & $2: 3$ & 7 \\
\hline 18 & $0: 4$ & 1 & $5: 0$ & 1 & $0: 4$ & 1 & $1: 4$ & 1 & & & $0: 4$ & 3 \\
\hline 19 & $3: 3$ & 1 & $0: 5$ & 1 & $3: 2$ & 1 & $5: 0$ & 1 & & & $3: 3$ & 3 \\
\hline 20 & $4: 1$ & 1 & $0: 4$ & 1 & & & $5: 1$ & 1 & & & $5: 0$ & 3 \\
\hline 21 & & & $4: 2$ & 1 & & & & & & & $4: 2$ & 2 \\
\hline 22 & & & & & & & & & & & $0: 5$ & 1 \\
\hline 23 & & & & & & & & & & & $5: 1$ & 1 \\
\hline \multicolumn{2}{|c|}{ Сумма } & 858 & & 718 & & 366 & & 517 & & 722 & & $\begin{array}{c}316 \\
8\end{array}$ \\
\hline \multicolumn{2}{|c|}{$\begin{array}{c}\text { Ранговое } \\
\text { среднее }\end{array}$} & 3,50 & & 4,44 & & 3,60 & & 4,6 & & 3,53 & & 3,91 \\
\hline \multicolumn{2}{|c|}{$\begin{array}{c}\text { Индекс } \\
\text { концентрации }\end{array}$} & 0,80 & & 0,747 & & 0,78 & & 0,78 & & 0,72 & & 0,81 \\
\hline \multicolumn{2}{|c|}{ Медиана } & 2 & & 3 & & 2 & & 4 & & 3 & & 3 \\
\hline
\end{tabular}

Произведя необходимые подсчеты, получаем следующие данные (см. табл. 2). В табл. 2 приведены как абсолютные частоты типов фигур, так и относительные (доли) среди всех фигур (указаны в скобках).

Доля симметричных фигур в нашем материале колеблется от 0,298 у Ремизова до 0,433 у Сологуба. Средняя доля равна 0,369 , а ее ошибка при $5 \%$-ном уровне значимости составляет 0,017 , образуя доверительный интервал $0,369 \pm 0,017$, в который попадает «малое» золотое сечение, равное 0,382 (дополняя его до единицы, получаем «большое» золотое сечение - 0,618). Аналогичная картина наблюдается и для доли фигур с левой и правой асимметрией. Прежде всего эти доли практически не различаются: мы имеем 0,319 для фигур с левой асимметрией и $0,311-$ с правой. Совместно эти доли составляют 0,630 при ошибке выборки, равной 0,024 , образуя доверительный интервал $0,63 \pm 0,024$. В этом 
случае золотое сечение тоже попадает в этот интервал. Обратим внимание на то, что полученные данные относятся только к усредненным показателям. Индивидуальные значения могут резко отличаться от золотого сечения. Однако в массе установленная закономерность действует.

Таблица 2. Симметрийные фигуры для пяти рассказов

\begin{tabular}{|l|c|c|c|c|c|c|}
\hline & Сологуб & $\begin{array}{c}\text { Зиновьева- } \\
\text { Аннибал }\end{array}$ & Пильняк & Ремизов & $\begin{array}{c}\text { Артем } \\
\text { Веселый }\end{array}$ & Сумма \\
\hline Симметричные & 362 & 253 & 147 & 151 & 258 & 1171 \\
& $(0,422)$ & $(0,352)$ & $(0,402)$ & $(0,298)$ & $(0,357)$ & $(0,369)$ \\
\hline Асимметричные & 193 & 294 & 61 & 221 & 243 & 1012 \\
влево & $(0,225)$ & $(0,409)$ & $(0,167)$ & $(0,436)$ & $(0,337)$ & $(0,319)$ \\
\hline Асимметричные & 302 & 171 & 158 & 135 & 221 & 987 \\
вправо & $(0,352)$ & $(0,238)$ & $(0,432)$ & $(0,266)$ & $(0,306)$ & $(0,311)$ \\
\hline Сумма & 857 & 718 & 366 & 507 & 722 & 3170 \\
\hline
\end{tabular}

Вернемся теперь к приблизительному равенству долей конструкций с левой и правой асимметрией. С точки зрения критерия Стьюдента, при 5\%-ном уровне значимости существенных различий между правым и левым ветвлением нет. Это означает, что в художественной прозе левое ветвление находится в равновесии с правым, т. е. здесь действует правило зеркальной симметрии. Но эта закономерность относится только к средним значениям по всем авторам. Между авторами различия могут быть весьма существенными. По-видимому, закон зеркальной симметрии характеризует литературнохудожественную систему в целом в понимании Ю.Н.Тынянова (Тынянов, 1929).

\section{4. Корреляция ранговых распределений синтаксических фигур}

Сходство и различие между пятью распределениями можно исследовать с помощью ранговой корреляции, которая напрашивается быть использованной самой структурой ранговых распределений.

Возьмем, например, двух каких-нибудь авторов из нашей пятерки и вычислим коэффициент ранговой корреляции. Пусть это будут Ф. Сологуб и Л. Зиновьева-Аннибал (см. табл. 1).

Ознакомившись с этими рядами, мы видим, что у Сологуба присутствует фигура 3:3, отсутствующая у Зиновьевой-Аннибал, а у последней видим две фигуры (0:5 и 5:0), которых нет у Сологуба, т. е. две этих совокупности отличаются по составу и количеству рангов. Это вынуждает нас вычислять коэффициент корреляции только для общего количества рангов, т. е. для 18. В данном исследовании вычислялся коэффициент ранговой корреляции Спирмена, формула которого имеет вид:

$$
\rho=1-\frac{6 d^{2}}{n\left(n^{2}-1\right)}, \text { где }
$$

$d$ - разность рангов одной и той же фигуры в двух ранжировках, а $n-$ число пар таких рангов.

В паре Сологуб-Зиновьева-Аннибал коэффициент корреляции оказался равным 0,905. Это значение довольно близко к 1 , поэтому корреляция здесь сильная.

В остальных парах ситуация примерно та же: весь набор коэффициентов корреляции больше 0,8 , что говорит о тесной связи между исследуемыми распределениями на ранговой оси.

\section{5. О законе Отто Бехагеля в русском рассказе}

Еще в начале XX века серьезный вклад в теорию синтаксиса и квантитативную лингвистику внес немецкий филолог Отто Бехагель. Он сформулировал несколько 
принципов расположения слов и частей речи в линейной развертке немецкого предложения. Совокупность этих принципов объединяет то, что называется «Законом Бехагеля». Центральное место в этой концепции занимает четвертый принцип этого закона, согласно которому их двух членов предложения более тяжелый (громоздкий) следует за более легким (компактным) (Behagel, 1909; Karl-Heinz Best, 2007). Закон Бехагеля тесно связан с законом экономии Джорджа Ципфа, который был сформулирован значительно позднее (Zipf, 1949).

Нас интересует в первую очередь именно этот четвертый принцип. Зависимые от синтаксического центра члены предложения могут выстраиваться слева и справа от него. При этом длины таких цепочек, как показано в табл. 1, не слишком велики. Цепочки, содержащие более трех элементов, крайне редки. Поэтому массивность членов предложения, входящих в такие последовательности, показана только для двухчленных и трехчленных структур, показанных в табл. 3 для пяти рассказов.

Из рис. 1 видно, что Отто Бехагель прав, говоря о большей громоздкости члена предложения, следующего за менее громоздким. Наше уточнение состоит в том, что мы рассматриваем пары и триады подряд следующих членов предложения, притом в постпозиции (позиции: $+1,+2$ и $+1,+2,+3$ ) и препозиции (позиции: $-1,-2$ и $-1,-2,-3$ ). Цепочки большей длины нами не рассматривались, так как они крайне редко встречаются в текстах, и здесь не набрать более или менее достоверной статистики. Но основная тенденция вырисовывается и при выбранной нами длине цепочки.

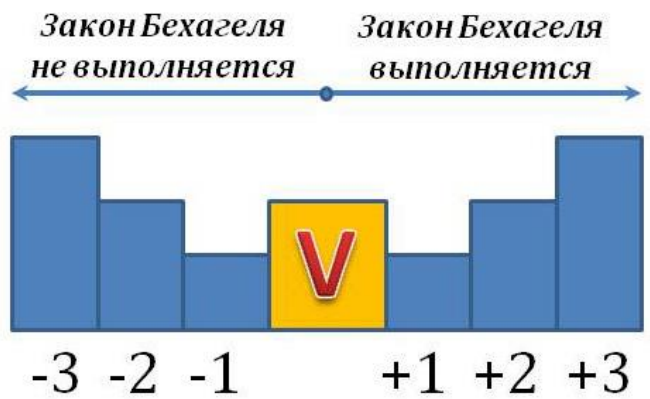

Рис. 1. Схема изменения объема члена предложения в зависимости от их расстояния от глагола-сказуемого

Наши результаты в основном не противоречат наблюдениям Бехагеля. Так, в постпозиции к вершине дерева во всех пяти рассказах присутствует возрастающий тренд, т. е. тяжелый член предложения следует за легким.

В препозиции ситуация не столь однозначна. Здесь доминирует обратная, убывающая тенденция - более легкий член предложения следует за более тяжелым. Минимальное значение обычно наблюдается в контакте с корнем дерева. Однако у ряда авторов во второй позиции в триадах мы зафиксировали провал, хотя в целом тенденция к строгому убыванию соблюдается. Сказанное не относится к бинарным структурам. Здесь нарушений основной тенденции нет.

В препозиции ситуация не столь однозначна. Здесь доминирует обратная, убывающая тенденция - более легкий член предложения следует за более тяжелым. Минимальное значение обычно наблюдается в контакте с корнем дерева. Однако у ряда авторов во второй позиции в триадах мы зафиксировали провал, хотя в целом тенденция к строгому убыванию соблюдается. Сказанное не относится к бинарным структурам. Здесь нарушений основной тенденции нет. 
Сказанное позволяет придти к заключению, подтверждающему в основном гипотезу Бехагеля на материале русской художественной прозы. Для усиления нашего вывод приведем данные о тестировании закона Бехагеля на материале русской научной прозы.

Таблица 3. Нагруженность левых и правых позиций словесным материалом при конструктивном центре предложения в русском рассказе

\begin{tabular}{|c|c|c|c|c|c|c|}
\hline Позиция & Сологуб & $\begin{array}{c}\text { Зиновьева- } \\
\text { Аннибал }\end{array}$ & Пильняк & Ремизов & $\begin{array}{c}\text { Артем } \\
\text { Веселый } \\
\end{array}$ & Сумма \\
\hline \multicolumn{7}{|c|}{ Трехчленные конструкции } \\
\hline-3 & $\begin{array}{c}50 \\
(1,613)\end{array}$ & $\begin{array}{c}77 \\
(1,116)\end{array}$ & $\begin{array}{c}11 \\
(1,100)\end{array}$ & $\begin{array}{c}110 \\
(4,782)\end{array}$ & $\begin{array}{c}50 \\
(1,6131)\end{array}$ & $\begin{array}{c}314 \\
(1,619)\end{array}$ \\
\hline-2 & $\begin{array}{c}31 \\
(1,348)\end{array}$ & $\begin{array}{c}69 \\
(0,831)\end{array}$ & $\begin{array}{c}10 \\
(1,250)\end{array}$ & $\begin{array}{c}23 \\
(0,920)\end{array}$ & $\begin{array}{c}31 \\
(1,348)\end{array}$ & $\begin{array}{c}194 \\
(1,016)\end{array}$ \\
\hline-1 & 23 & 83 & 8 & 25 & 23 & 191 \\
\hline+1 & $\begin{array}{c}38 \\
(1,652)\end{array}$ & $\begin{array}{c}48 \\
(1,655)\end{array}$ & $\begin{array}{c}87 \\
(3,346)\end{array}$ & $\begin{array}{c}23 \\
(1,150)\end{array}$ & $\begin{array}{c}38 \\
(1,652)\end{array}$ & $\begin{array}{c}215 \\
(1,853)\end{array}$ \\
\hline+2 & 117 & 147 & 97 & 68 & 117 & 508 \\
\hline+3 & $\begin{array}{c}208 \\
(1,776)\end{array}$ & $\begin{array}{c}246, \\
(1,672)\end{array}$ & $\begin{array}{c}160, \\
(1,649)\end{array}$ & $\begin{array}{c}246 \\
(3,618) \\
\end{array}$ & $\begin{array}{c}208 \\
(1,778)\end{array}$ & $\begin{array}{c}1068, \\
(2,102)\end{array}$ \\
\hline \multicolumn{7}{|c|}{ Двухчленные конструкции } \\
\hline-2 & $\begin{array}{c}171 \\
(1,413)\end{array}$ & $\begin{array}{c}172 \\
(1,343)\end{array}$ & $\begin{array}{c}153 \\
(1,800) \\
\end{array}$ & $\begin{array}{c}151 \\
(1,696) \\
\end{array}$ & $\begin{array}{c}171 \\
(1,413) \\
\end{array}$ & $\begin{array}{c}758 \\
(1,441) \\
\end{array}$ \\
\hline-1 & 121 & 128 & 85 & 89 & 121 & 526 \\
\hline+1 & 14 & 27 & 14 & 18 & 14 & 89 \\
\hline+2 & $\begin{array}{c}23 \\
(1,643) \\
\end{array}$ & $\begin{array}{c}29 \\
(1,074)\end{array}$ & $\begin{array}{c}26, \\
(1,857)\end{array}$ & $\begin{array}{c}20 \\
(1,111)\end{array}$ & $\begin{array}{c}23 \\
(1,643)\end{array}$ & $\begin{array}{c}116 \\
(1,303)\end{array}$ \\
\hline
\end{tabular}

Таблица 4. Нагруженность левых и правых позиций словесным материалом при конструктивном центре в русской научной прозе

\begin{tabular}{|c|c|c|c|c|c|}
\hline \multicolumn{7}{|c|}{ Трехчленные структуры } \\
\hline \multicolumn{3}{|c|}{ Левые } & \multicolumn{3}{|c|}{ Правые } \\
\hline 4 & -2 & -1 & +1 & +2 & +3 \\
\hline 44 & 51 & 27 & 11 & 24 & 73 \\
\hline \multicolumn{3}{|c|}{ Двухчленные структуры } \\
\hline \multicolumn{3}{|c|}{ Левые } & \multicolumn{3}{|c|}{ Правые } \\
\hline & -2 & -1 & +1 & +2 & \\
\cline { 2 - 5 } & 187 & 202 & 34 & 133 & \\
\hline
\end{tabular}

Ситуация в табл. 4 - примерно та же, что и в табл. 3 , с тем отличием, что в табл. 4 в левой триаде в позиции "-2" наблюдается выпад, а не провал. Это, по-видимому, означает, что данная позиция в нашем исследовании не обрела устойчивости. Это вынуждает провести повторные исследования. В остальном картина в художественной и научной прозе совпадает, что свидетельствует о межжанровой универсальности закона Бехагеля.

\section{6. Заключение}

Ранговые порядки в рассказах писателей первой трети XX в. очень близки, тогда как их частотные структуры контрастируют. 
Это означает, что в художественной прозе левое ветвление находится в равновесии с правым, т. е. здесь действует правило зеркальной симметрии. Но эта закономерность относится только к средним значениям по всем авторам. Между отдельными авторами различия могут быть весьма существенными. По-видимому, закон зеркальной симметрии характеризует литературно-художественную систему в целом в понимании Ю. Н. Тынянова.

Закон нарастающих членов предложения соблюдается для правоветвящихся структур, в левосторонних структурах в целом порядок следования обратный, т. е. здесь действует закон убывающих членов предложения. Но и здесь возможны корректировки, так как в тернарных структурах средний член может нарушать это правило.

Работа выполнена при поддержке Российского фонда фундаментальных исследований, грант № 17-29-09173 офи_м «Русский язык на рубеже радикальных исторических перемен: исследование языка и стиля предреволюционной, революционной и постреволюционной художественной прозы методами математической и компьютерной лингвистики (на материале русского рассказа)».

\section{Литература}

[1] Буторов В.Д. Моделирование синтаксиса естественного языка / Прикладное языкознание: Учебник. Л.В.Бондарко, Л.А.Вербицкая, Г.Я.Мартыненко и др. Отв. ред. А.С.Герд. СПб.: Изд-во С.-Петерб. ун-та, 1996.

[2] Гребенников А.О. (Сост.) Частотный словарь рассказов А. П. Чехова / Под ред. Г.Я.Мартыненко. СПб.: Изд-во Санкт-Петерб. ун-та, 1999.

[3] Мартыненко Г. Я. О состоятельности порядковых статистик частотных словарей // Интернет и современное общество: сборник тезисов докладов / Труды XX Международной объединенной научной конференции «Интернет и современное общество» (IMS-2017), СПб., 21-23 июня 2017 г. СПб: Университет ИТМО, 2017. C. 98 - 106. URL: https://openbooks.itmo.ru/ru/file/6512/6512.pdf (дата обращения: 05.07.2019).

[4] Мартыненко Г.Я. Категория симметрии в словесности / Verba magistra. Сборник научных статей памяти профессора Александра Сергеевича Герда. - СПб.: НесторИстория, 2016. С. $396-413$.

[5] Мартыненко Г.Я. Основы стилеметрии. Л.: Изд-во Ленингр. ун-та, 1988.

[6] Мартыненко Г.Я. Статистические характеристики ранговых распределений. Ученые записки Тартуского ун-та: Квантитативная лингвистика и автоматический анализ текстов, Тарту, 1989. С. $50-68$.

[7] Тынянов Ю.Н. Архаисты и новаторы, М.: Прибой, 1929.

[8] Фитиалов С.Я. Об эквивалентности грамматик НС и зависимостей / Проблемы структурной лингвистики 1967. М., 1968. С. 72 - 102.

[9] Best K.-H. Otto Behaghel (1854-1936), Glottometrics. 14, 2007. P. 80 - 86.

[10] Behaghel O. Beziehungen zwischen Umfang und Reihenfolge von Satzgliedern. In: Indogermanische Forschungen 25, 1909. P. 110 - 142.

[11]Zipf G. K. Human Behavior and the Principle of Least Effort. Cambridge, MA: AddisonWesley, 1949. 


\title{
Symmetrics of Syntactic Figures in Fiction: the Case of Russian Short Stories of the 20th Century
}

\begin{abstract}
G. Martynenko ${ }^{1}$, T. Sherstinova ${ }^{1,2}$
${ }^{1}$ St. Petersburg State University, ${ }^{2}$ National Research University Higher School of Economics

The article describes the study of linearized subordination structures and the dependency tree width. The study is quantitative in nature. It is related with the rank distributions of subordination structures, in which both the number of dependent members and their right-branching/leftbranching variants are concerned. The similarity of rank structures for different authors is observed despite a significant difference in frequency characteristics between the authors. Besides, the work deals with the symmetry properties of these structures, and their bias towards the mirror symmetry and the golden symmetry. An approximate equilibrium of the left and right width in the Russian short story of the first third of the 20th century is revealed. Otto Behaghel's law of the increasing members was tested and adjusted for the Russian language.
\end{abstract}

Keywords: Russian short story, rank distributions, rank average, concentration index, syntactic figures, right and left width, bush symmetry, mirror symmetry, gold symmetry, Behaghel's law

Reference for citation: Martynenko G.Y., Sherstinova T.Y. Symmetrics of Syntactic Figures in Fiction: the Case of Russian Short Stories of the 20th Century // Computer Linguistics and Computing Ontologies. Vol. 3 (Proceedings of the XXII International Joint Scientific Conference «Internet and Modern Society», IMS-2019, St. Petersburg, June 19-22, 2019). - St. Petersburg: ITMO University, 2019. P. 116 - 123. DOI: 10.17586/2541-9781-2019-3-116-123

\section{Reference}

[1] Butorov V.D. Modelirovanie sintaksisa estestvennogo jazyka // Prikladnoe jazykoznanie: Uchebnik. L.V.Bondarko, L.A.Verbickaja, G.Ja.Martynenko i dr. Otv. red. A.S.Gerd. St. Petersburg.: Izd-vo S.-Peterb. un-ta, 1996. (in Russian).

[2] Grebennikov A.O. (Sost.) Chastotnyj slovar' rasskazov A. P. Chekhova / Pod red. G.Ja.Martynenko. St. Petersburg.: Izd-vo Sankt-Peterb. un-ta, 1999. (in Russian).

[3] Martynenko G. Ja. O sostojatel'nosti poryadkovykh statistik chastotnykh slovarej // Internet i sovremennoe obshchestvo: sbornik tezisov dokladov / Trudy XX Mezhdunarodnoj ob'edinennoj nauchnoj konferencii «Internet i sovremennoe obshchestvo» (IMS-2017), Sankt-Petersburg, 2123 ijunja 2017, St. Petersburg.: Universitet ITMO, 2017. P. 98-106. URL: https://openbooks.itmo.ru/ru/file/6512/6512.pdf (last accessed: 05.07.2019). (in Russian).

[4] Martynenko G.Ja. Kategoriya simmetrii v slovesnosti / Verba magistra. Sbornik nauchnykh statej pamyati professora Aleksandra Sergeevicha Gerda. - Sankt-Petersburg: Nestor-Istorija, 2016. P. 396 - 413. (in Russian).

[5] Martynenko G.Ja. Osnovy stilemetrii. Leningrad: Izd-vo Leningr. un-ta, 1988. (in Russian).

[6] Martynenko G.Ja. Statisticheskie kharakteristiki rangovykh raspredelenij. Uchenye zapiski Tartuskogo un-ta: Kvantitativnaja lingvistika i avtomaticheskij analiz tekstov, Tartu, 1989. P. 50 68. (in Russian).

[7] Tynyanov Ju.N. Arkhaisty i novatory, M.: Priboj, 1929. (in Russian).

[8] Fitialov S.Ja. Ob ekvivalentnosti grammatik NS i zavisimostej / Problemy strukturnoj lingvistiki 1967. M., 1968. P. 72 - 102. (in Russian).

[9] Best K.-H. Otto Behaghel (1854-1936), Glottometrics. 14, 2007, P. 80 - 86.

[10] Behaghel O. Beziehungen zwischen Umfang und Reihenfolge von Satzgliedern. In: Indogermanische Forschungen 25, 1909. P. 110 - 142.

[11]Zipf G. K. Human Behavior and the Principle of Least Effort. Cambridge, MA: Addison-Wesley, 1949. 